\title{
dosalgarves

\section{A literatura como pretexto de viagem: De Lisboa a Santarém com Almeida Garrett}

\section{Literature as pretext for travel: From Lisbon to Santarém with Almeida Garrett}

\author{
Ana Cláudia Boavida Salgueiro da Silva \\ Centro de Estudos em Letras, Universidade de Évora, Portugal \\ anabssilva@gmail.com
}

\begin{abstract}
Resumo
Este trabalho apresenta uma proposta de visita, mapeada a partir da obra Viagens na Minha Terra de Almeida Garrett (1799-1854), a qual potencia a criação de um amplo número de lugares literários. A partir da análise do trajeto feito por Garrett, cuja viagem tem início no Terreiro do Paço, em Lisboa, rumo a Santarém, é desenvolvida a vivência de uma experiência turístico-literária, através das descrições que o autor faz dos locais por onde passa, destacando a literatura como pretexto de viagem e, por conseguinte, suscitando uma visita pela região ribatejana.
\end{abstract}

Palavras-chave: Turismo literário; viagens literárias; lugares literários; Almeida Garrett.

\begin{abstract}
This article presents a proposal for an itinerary, mapped from the literary work Viagens na Minha Terra by Almeida Garrett (1799-1854), which has the potential to create of a large number of literary places. From the analysis of Garrett's own itinerary that starts at the Terreiro do Paço, in Lisbon, and ends at Santarém, a literary tourism experience is developed, through the descriptions that the author makes of the places he visits, highlighting literature as a pretext for travelling and, consequently, arousing interest in a visit to the region of Ribatejo.
\end{abstract}

Keywords: Literary tourism; literary trips; literary places; Almeida Garrett.

\section{Introdução}

O grande potencial turístico de Portugal assenta, manifestamente, em fatores como o clima, as paisagens naturais, a herança patrimonial, a riqueza gastronómica e a hospitalidade da população.

Efetivamente, Portugal é considerado um destino turístico de excelência (Barros, 2015: 14), pelo que, confirmando a asserção de que o turismo é, atualmente, um dos principais motores da economia portuguesa, ${ }^{1}$ este trabalho visa conceder o devido destaque a uma das

\footnotetext{
${ }^{1}$ Comprova-se esta situação através dos dados do Instituto Nacional de Estatística que, “[... ] tendo por base a informação mais recente divulgada pelo Banco de Portugal relativa à Balança de Pagamentos, salient[a] o aumento de $23,0 \%$ no saldo da rubrica Viagens e Turismo em 2017, claramente acima do aumento de $12,7 \%$ em 2016. Para o aumento do saldo em 2017 contribuiu a aceleração do crescimento das receitas/créditos para 19,5\%, face a $+10,7 \%$ no ano precedente, as quais totalizaram 15,2 mil milhões de euros [... ]" (Instituto Nacional de Estatística [INE], 2018: 5). 
modalidades - o turismo literário -, propondo uma visita turístico-literária inspirada na novela Viagens na Minha Terra, de Almeida Garrett (1846). Esta proposta é construída com o levantamento das referências espaciais indicadas na obra e respetivas citações, assim como com pesquisa bibliográfica sobre o turismo e o turismo literário.

\section{A relevância do turismo literário}

Centrado no ato de viajar, o turismo consiste, segundo a Organização Mundial do Turismo das Nações Unidas, no conjunto de atividades realizadas pelos indivíduos, durante as suas viagens e estadias em lugares diferentes da sua residência habitual, por um período de tempo consecutivo inferior a um ano, cuja motivação excetua o exercício de qualquer atividade remunerada nos locais visitados.

Nascido no século XIX, o turismo desenvolve-se ao longo dos tempos, atingindo uma acentuada importância na economia mundial, adveniente da movimentação de turistas, impulsionadora do aumento do consumo e da produção de bens e serviços: "[... ] De acordo com a Organização Mundial do Turismo, a atividade turística contribui para o crescimento económico, para a criação de emprego e para a redução dos desequilíbrios da balança de pagamentos [...]" (Barros, 2015: 9-10).

Portugal não é exceção e, como tal, o turismo constitui, hoje em dia, um dos mais importantes setores da sua economia, situando-se entre os países com maior procura turística em todo o mundo, conforme atesta a atribuição, em 2017, do prémio de "Melhor Destino Turístico do Mundo", tornando-se o primeiro país europeu a conquistar esta distinção nos World Travel Awards.

Deste modo, de entre as diferentes tipologias de turismo, destaca-se neste trabalho o turismo literário, caracterizado pela deslocação de pessoas com o objetivo de vivenciarem experiências significativas e cujo interesse reside, principalmente, no gosto pela literatura: "[... ] O turismo literário, turismo cultural diretamente associado à visita de locais reconhecidos pela sua relação com obras literárias e/ou autores, tem vindo a ocupar um espaço cada vez mais relevante no universo do turismo, encontrando-se neste momento em grande expansão, quer em Portugal quer noutros países [... ]" (Neves, 2010: 265).

Com efeito, o desenvolvimento desta modalidade é cada vez mais evidente, sendo que, ao visitarem determinados "lugares literários", os turistas apreendem "[... ] novos objetos de conhecimento nascidos na fronteira da ficção literária e da realidade [...]" (Quinteiro, Baleiro \& Santos, 2016: 8), experienciando vivências e realidades culturais diversificadas.

Sensíveis às culturas locais, os turistas podem, consequentemente, usufruir de uma vasta oferta turística e de uma multiplicidade de produtos, aliados a um turismo de qualidade que enriquece os seus padrões culturais e literários.

\section{De Lisboa a Santarém com Almeida Garrett}

Neste âmbito, evidencia-se a obra Viagens na Minha Terra, cujo título é, desde logo, apelativo, pois induz os leitores a viajarem no território português. Todavia, o autor, apesar de muitas viagens, que são jornadas mentais e sentimentais, reflexões e críticas, numa digressão pela 
paisagem, pela história, pela literatura e pela cultura portuguesas, centra-se na região ribatejana, nomeadamente, em Santarém.

Em 1843, surgem, em folhetim, na Revista Universal Lisbonense, os primeiros capítulos de uma novela inovadora no panorama literário português, intitulada Viagens na Minha Terra, “[... ] sem dúvida [...], uma das mais originais, mais interessantes, mais complexas obras da literatura portuguesa [...]” (Régio, 1994: 69).

Publicada em volume, em 1846, esta novela é o ponto de partida da moderna prosa literária portuguesa, não só pela mistura de estilos e pelo cruzamento de uma linguagem clássica e coloquial, mas também pela análise da situação política, social e cultural do país e pela simbologia que as personagens Frei Dinis e Carlos representam - o Portugal velho absolutista e o espírito renovador e liberal, respetivamente.

Nas palavras de Ofélia Paiva Monteiro (1976: 29), Garrett “[... ] adoptava já um assunto nitidamente contemporâneo, traduzindo na forma como postulava os problemas a sua capacidade para argutamente julgar a sociedade nova [...]".

De facto, Viagens na Minha Terra combina a narração em torno dos primos Carlos e Joaninha e o estilo digressivo da viagem real efetuada pelo escritor, entre Lisboa e Santarém, a convite do político liberal Passos Manuel (1801-1862). É a partir desta viagem que, neste trabalho, se propõe a criação de uma visita turístico-literária.

\subsection{A partida de Lisboa e as zonas ribeirinhas}

A viagem faz recuar os leitores-turistas até ao século XIX, mais precisamente, a 17 de julho de 1843, cuja digressão tem início no Terreiro do Paço, em Lisboa, onde o autor apanha o vapor "Vila Nova" rumo a Santarém:

[... ] Vou nada menos que a Santarem: e protesto que de quanto vir e ouvir, de quanto eu pensar e sentir se hade fazer chronica. Era uma idea vaga [... ], que eu tinha ha muito de ir conhecer as riccas varzeas d' esse Ribatejo, e saudar em seu alto cume a mais historica e monumental das nossa villas [...] (Garrett, 1846a: 2).

Na verdade, Viagens na Minha Terra apresenta sítios e ambientes (ver), conversas (ouvir), considerações (pensar) e confidências (sentir) que tornam possível o delinear de uma visita em que se associa turismo e literatura.

Citando Rita Baleiro e Sílvia Quinteiro (2017: 15), “[... ] o turismo literário apresenta como traço específico e diferenciador o facto de implicar a deslocação a lugares, de algum modo, relacionados com a literatura e os seus autores. Lugares que apelidamos de literários por serem frações de espaço nos quais há uma qualquer ligação à literatura [... ]".

Tal sucede com a obra de Garrett, na qual são representados diferentes lugares que poderão ser interpretados como lugares literários - aqueles “[... ] lugares que [o] inspiraram ou serviram de cenário nos seus textos [... ]" (Baleiro \& Quinteiro, 2017: 15) e a partir dos quais se pode propor uma visita.

O autor começa por chamar a atenção dos leitores para o panorama que observa aquando da partida: "[...] Assim vamos de todo o nosso vagar contemplando este majestoso e pittoresco amphitheatro de Lisboa oriental, que é, vista de fóra, a mais bella e grandiosa parte da cidade, a mais characteristica [...]" (Garrett, 1846a: 4).

Outrora, nesta zona da capital portuguesa, existiam quintas e conventos, sendo que a sua morfologia foi alterada, não só com o terramoto de 1755, mas também com a extinção das 
ordens religiosas e com a instalação gradual de fábricas, facilitada pela proximidade do rio Tejo e pela instalação da linha de caminho de ferro.

E o autor continua:

[... ] A um lado a immensa majestade do Tejo em sua maior extensão e podêr, que alli mais parece um pequeno mar mediterraneo; do outro a frescura das hortas e a sombra das árvores, palacios, mosteiros, sitios consagrados todos a recordações grandes ou queridas. Que outra sahida tem Lisboa que se compare em belleza com ésta? Tirado Bellem, nenhuma [...] (idem: 4-5).

Evidenciando a relevância do rio Tejo e a harmonia patente nas edificações que se avistam, Garrett realça a perspetiva observada a partir do Terreiro do Paço, a praça ribeirinha da Baixa de Lisboa, que hoje constitui uma das maiores praças da Europa.

Aquando do terramoto de 1755, existia o Palácio Real, em cuja biblioteca estavam guardados milhares de volumes e centenas de obras de arte que foram destruídos. O Palácio Real foi a residência oficial da família real portuguesa, que substituiu o Paço da Alcáçova (edificação medieval inscrita no castelo de São Jorge). A sua construção teve início em 1498, por determinação de D. Manuel I (1469-1521), aquando da descoberta do caminho marítimo para a Índia e do estabelecimento do monopólio português do comércio das especiarias do Oriente. Atualmente, os edifícios que circundam a praça são governamentais.

O autor alude também a uma das freguesias lisboetas que deve o seu nome a Santa Maria de Belém, invocada por D. Manuel I que, em 1495, decidiu fundar o Mosteiro de Santa Maria de Belém, doado aos monges da Ordem de São Jerónimo e conhecido como Mosteiro dos Jerónimos.

Tal como Garrett, partindo de Lisboa, Tejo acima, a viagem prossegue: “[... ] Já saudâmos Alhandra, a toireira; Villa-franca, a que foi de Xira, e depois da Restauração, e depois outra vez de Xira, quando a tal restauração cahiu [...]" (idem: 5).

De realçar duas situações particulares: por um lado, avulta uma das características da zona - a tauromaquia; por outro, e, implicitamente, é feita referência à Vilafrancada (1823), a revolta levada a efeito por D. Miguel (1802-1866) contra a Constituição de 1822. Na sequência dos acontecimentos, Vila Franca de Xira foi renomeada para Vila Franca da Restauração, sendo que o nome não perdurou, visto que, após o fracasso da Abrilada (1824), que pôs fim à sublevação dos miguelistas, voltou ao nome original. Vila Franca é sede de concelho, com seis freguesias, e foi elevada a cidade em junho de 1984.

Avançando, chegamos a Vila Nova da Rainha, freguesia do concelho da Azambuja, elevada a vila em julho de 2001, sendo nesta localidade que o nobre e militar Nuno Álvares Pereira - o Santo Condestável (1360-1431) - se casou. Nesta localidade, também foi instalado o primeiro centro de formação de aviadores.

Garrett refere-se ao local de desembarque como "[... ] o mais feio pedaço de terra alluvial em que ainda poisei os meus pés [...]" (idem: 16), prosseguindo o passeio até à Azambuja, também sede de município, com sete freguesias e que, desde 2004, integra a Comunidade Urbana da Lezíria do Tejo, sendo considerada a porta de entrada da Grande Lisboa, quer por autoestrada, quer por caminho de ferro.

O autor elogia a localidade, aludindo à fertilidade que caracteriza a região ribatejana, utilizando uma metáfora para se referir ao rio Tejo (o mais extenso da Península Ibérica) como o "Nilo português" (o mais extenso do mundo), evidenciando o facto de as suas águas 
inundarem os campos de cultivo para os enriquecer: “[... ] Ahi está a Azambuja, pequena mas não triste povoação, com visiveis signaes de vida, aceadas e com ar de confôrto as suas casas. É a primeira povoação que dá indicio de estarmos nas ferteis margens do Nilo portuguez [... ]" (idem: 20).

Segundo Michel Collot (2012: 29), as metáforas espaciais demonstram "[... ] que o espaço não é, para os escritores, somente um cenário exterior, mas a expressão de valores e de significações de seu imaginário mais íntimo [...]”.

Partindo da estalagem da Azambuja, seguimos Almeida Garrett em direção ao pinhal, cuja ambiência o desilude:

Este é que é o pinhal da Azambuja?

Não póde ser.

[...] Uns poucos de pinheiros raros e infezados atravez dos quaes se estão quasi vendo as vinhas e olivedos circumstantes!... É o desapontamento mais chapado e solemne que nunca tive na minha vida [... ] (Garrett, 1846a: 39, 42).

Crê-se que o pinhal da Azambuja ou das Virtudes foi mandado plantar por D. Dinis (1261-1325), constituindo, atualmente, um local de lazer, com uma paisagem agradável, onde se pode praticar atividade física. De acentuada importância natural, este pinhal acolhe um considerável conjunto de árvores, tendo sido relevante no fornecimento de madeira para as naus dos Descobrimentos e para as estacas que suportam a baixa pombalina.

A visita continua até ao Cartaxo, precisamente, até ao grande café da localidade:

[... ] Fazem idea do que é o café do Cartaxo? Não fazem. Se não viajam, se não sahem, se não vêem mundo ésta gente de Lisboa! E passam a sua vida entre o Chiado, a rua do Oiro e o theatro de San' Carlos, como hãode alargar a esphera de seus conhecimentos, desinvolver o espirito, chegar à altura do seculo? [... ] (idem: 60-61).

Nesta passagem subjaz uma crítica aos que não viajam e aos que se cingem aos locais mais concorridos de Lisboa. Na opinião do narrador, pessoas assim não enriquecem os seus conhecimentos sobre outros lugares do território português.

Ao incentivar tais deslocações, as mesmas permitiriam, nas palavras de Garrett, "desenvolver o espírito e chegar à altura do século"; promovendo uma abertura de mentalidades e, por conseguinte, favorecendo o desenvolvimento e a evolução da sociedade portuguesa, arrisca-se a afirmação de que o autor já preconizava o conceito de turismo.

De saída do Cartaxo, município com seis freguesias (distrito de Santarém), elevado a cidade em junho de 1995, ponto de passagem para o interior do país, quer por via fluvial, quer por via terrestre e distinguido pela sua riqueza vinhateira (um dos produtos turísticos mais apreciados), este espaço tornou-se, desde finais do século XIX, no centro de produção vinícola mais característico do Vale do Tejo. Daqui prossegue a visita até à charneca: “[... ] Bella e vasta planicie! Desafogada dos raios do Sol, como ella se desenha ahi no horisonte tam suavemente! Que delicioso aroma selvagem que exhalam éstas plantas, acres e tenazes de vida, que a cobrem, e que resistem verdes e viçosas a um sol portuguez de julho! [... ]" (idem: 72).

Esta descrição exalta a beleza da charneca, sobressaindo a mistura das sensações visuais e olfativas, de onde se destaca a sensibilidade cromática que define e completa o quadro. 
Chegamos, finalmente, ao Vale de Santarém, um lugar privilegiado pela natureza, cuja presença é, na opinião de Helena Buescu (1997: 368), “[... ] muito forte na narrativa garrettiana [... ], seja através de descrições seja através de relações simbólicas [...]”.

Vila desde 1995, o Vale de Santarém fica situado na margem direita do rio Tejo, sendo essencialmente agrícola, mas onde a indústria e o comércio também desempenham um papel preponderante para a sua economia.

E Garrett refere:

[...] Ca estâmos n' um dos mais lindos e deliciosos sitios da terra: o valle de Santarem, patria dos rouxinoes e das madresilvas, cincta de faias bellas e de loureiros viçosos. D'isto é que não tem Paris, nem França nem terra alguma do occidente senão a nossa terra, e vale bem por tantas, tantas coisas que nos faltam (Garrett, 1846a: 90).

Enaltecendo a harmonização do conjunto paisagístico, em que avulta a defesa do que é nacional como uma das características mais relevantes do Romantismo, patente nesta obra "a nossa terra" -, o autor detém-se na valorização da natureza como um espaço salutar que devolve ao ser humano a sua pureza; um lugar aprazível, equilibrado e simples, privilegiado para a reflexão; um local paradisíaco que exclui os vícios e as paixões mundanas:

O valle de Santarem é um d' estes logares privilegiados pela natureza, sitios amenos e deleitosos em que as plantas, o ar, a situação, tudo está n'uma harmonia suavissima e perfeita: não ha alli nada grandioso nem sublime, mas ha uma como symetria de côres, de sons, de disposição em tudo quanto se ve e se sente, que não parece senão que a paz, a saude, o socêgo do espirito e o repouso do coração devem viver alli, reinar alli um reinado de amor e benevolência [...]. Imagina-se por aqui o Eden que o primeiro homem habitou com a sua innocencia e com a virgindade do seu coração [... ] (idem: 92).

É, pois, no Vale, que Garrett observa uma janela “[... ] larga e baixa; parece mais ornada e tambem mais antiga que o resto do edificio que, todavia, mal se ve... Interessou-me aquella janella [... ]" (idem: 92-93). É a partir desta observação que o autor constrói a novela da menina dos rouxinóis, cuja narrativa se desenrola em plena guerra civil (1832-1834), entre liberais e miguelistas, ou seja, a guerra da monarquia constitucional contra o absolutismo monárquico.

Dissertando sobre a história de Joaninha e Carlos, ${ }^{2}$ o autor demora a retomar o seu caminho e justifica: "[... ] Vem para mostrar que a história, lida ou contada nos proprios sitios em que se passou, tem outra graça e outra fôrça [... ]" (idem: 8 ).

Tal é o objetivo desta visita turístico-literária que propõe a deslocação a estes espaços que recordam contextos de outros tempos e concedem um maior pragmatismo à representação do espaço no texto: "[...] Ao andar nas ruas apreende-se o lugar, ao descrever as ruas (re)constrói-se o local, perpetuando, na sua representação, o potencial da mesma enquanto espaço de sociabilidade, de vivências e de afetos [... ]" (Almeida \& Oliveira, 2018: 39).

\footnotetext{
${ }^{2}$ A história de Carlos é a história de Garrett que concebe o amor como um estado intenso, em que autor e personagem se identificam: "[...] A história dos amores passados de Carlos, em Inglaterra, esta paixão ainda incandescente que tem por Georgina dos olhos azuis, era uma realidade na vida de Garrett exilado - tal como a paixão que Carlos experimentara antes por uma Laura de olhos cor de avelã, irmã de Georgina, enquanto sonhava com Joaninha [... ]" (França, 1993: 115).
} 
Deste modo, os turistas-leitores acompanham a visita turística com a leitura de excertos da obra em estudo, os quais determinam os lugares da narrativa, o que atribui um novo sentido a esses lugares, assim como promove a divulgação do autor e da sua obra: "[... ] Cada vez mais o indivíduo procura lugares de literatura [... ]. Cada vez mais as localidades promovem eventos culturais e literários que divulgam o seu património. Mas também cada vez mais o leitor procura os lugares da literatura, isto é, os lugares do mundo real que leem nas histórias da literatura de ficção [...]" (Neves, 2010: 265-266).

Na verdade, Viagens na Minha Terra pode ser um guia de turismo, com uma intenção que origina a sua redação: Garrett deseja conhecer o Ribatejo e aceita o convite de Passos Manuel para visitar Santarém, o que se torna culturalmente interessante por motivar a descoberta de lugares que foram essenciais à inspiração do autor.

Viajar pela região ribatejana, com orientação da escrita garrettiana e, simultaneamente, viajar pela história e pela natureza, deter-se nos lugares e conhecê-los é o propósito desta visita, cuja conceção se baseia na procura do mundo real nos lugares da literatura.

Segundo Mike Robinson,

[... ] escrever sobre a experiência de viagens e visitas a «outros» lugares é tão antigo como o próprio viajar [...]. Este partilhar de experiências em diferentes lugares desempenha várias funções. Para o escritor, legitima os episódios de viagem como um acontecimento de vida vivida de maneira partilhada e social [... ]. Para o leitor, os livros de viagens facilitam esta escapada e permitem-Ihe uma passagem segura e fácil para lugares que poderão nunca visitar directamente [... ] (Robinson, 2004: 341).

\subsection{Visita a Santarém}

Chegamos, finalmente, a Santarém (de "Scallabis"; mais tarde, "Sancta Irene"), capital do Ribatejo, que, "[...] na sua planura fofa e ubérrima, na melodia dos seus chocalhos e na harmonia da sua cor, [... e é um grito de felicidade incontida no corpo da nação. É uma faixa escarlate e briosa à cinta de Portugal [... ]" (Torga, 2015 [1950]: 76).

Situada num planalto, sobranceiro ao rio Tejo, Santarém propicia um panorama que deixa o turista seduzido: "[.... $\mathrm{O}$ O mais bello comtudo de seus ornatos e glórias suburbanas, ainda o possue a nobre villa, não lh'o destruiram de todo; são os seus olivaes [... ]. Reconheceu-os o meu coração e alegrou-se de os ver; saudei n'elles o symbolo patriarchal de nossa antiga existencia [...]" (Garrett, 1846b: 12).

A região apresenta três áreas diferenciadas: a lezíria, formada pelas planícies inundáveis pelo Tejo, com solos de boa qualidade; os "bairros", constituídos por culturas arbóreas, situadas a norte, na margem direita do rio; a charneca, situada na margem esquerda do rio e composta por revestimento florestal, assim como por culturas de cereais e vinha.

Assim, damos início à segunda parte da visita, em que Garrett exalta a imutabilidade da paisagem, lamentando, no entanto, a degradação do que melhor identifica a localidade no âmbito do património construído - o gótico. Pelo seu imponente passado artístico, Santarém é considerada a "capital do gótico português", designação adveniente das manifestações artísticas que tiveram o seu apogeu entre os séculos XIV e XV: "[...] Em Santarém, cada pedra é um monumento e cada monumento, um padrão de glória nacional [...]” (Brandão apud Azevedo, 1975: 273).

De facto, chegaram a existir, nesta localidade, catorze conventos e trinta e seis igrejas que foram destruídos, progressivamente, não só pelo terramoto de 1755, mas também pelas 
invasões francesas que causaram danos à população e ao património; e ainda pelo vandalismo da revolução liberal que destruiu os meios de subsistência, provocando a delapidação dos bens, assim como pela extinção das ordens religiosas que provocou o fecho dos conventos e a consequente retirada do património.

Santarém, elevada à categoria de cidade em 1868, é uma cidade histórica, de cujos filões só ficaram escombros no século XIX, estando ligada a muitos episódios decisivos da história nacional, como, por exemplo, a aclamação de D. João II (1455-1495) e a transformação em quartel-general, aquando das invasões francesas pelo marechal Massena (1756-1817), e por D. Miguel nas lutas liberais:

[...] Santarém identifica-se com o rio a tal ponto que dele tomou a força situacional, o sabor da revolta guerreira e o talento da estratégia. Vila portuária, foi princesa no reino português e abrigo regular das cortes, e assim se manteve na crista da História portuguesa, sempre, ora levantando monumentos, produzindo obras de arte, tomando posição nos momentos conturbados, ora vilipendiando o seu património e albergando usurpadores […] (Serrão, 1990: 110).

Por isso, Almeida Garrett afirma: "[...] Santarem é um livro de pedra em que a mais interessante e mais poetica parte das nossas chronicas está escripta [... ]” (Garrett, 1846b: 32).

Favorecida pela posição geográfica, pela fertilidade do solo, pela amenidade do clima e pela riqueza artística, Santarém possui diferentes pontos de interesse turístico: “[...] A majestosa entrada da grande villa está deante de mim [...]. Fóra-de-villa é um vasto largo, irregular e caprichoso como um poema romantico [...]. Palacios, conventos, egrejas occupam gravemente e tristemente os seus antigos logares, infileirados sem ordem aos lados d' aquella immensa praça [... ]" (Garrett, 1846b: 13).

Espaço extramuros, detentor de uma fileira de mosteiros medievais, o Campo Fora-de-Vila manteve-se como espaço primordial através da realização de mercados, feiras e exposições, sendo o ponto de partida desta visita: "[... ] À esquerda o immenso convento do Sítio ou de Jesus, ${ }^{3}$ logo o das Donas, ${ }^{4}$ depois o de San' Domingos, célebre pelo jazigo de [... ] San'Frei Gil [...]. Defronte o antiquissimo mosteiro das Claras, e ao pé as baixas arcadas gothicas de San' Francisco [... ]. À direita o grandioso edificio philippino [... ], o Collegio [... ]" (idem: 14).

Nesta visita, Garrett é bastante explícito, identificando e localizando as diversas construções religiosas, hoje muitas delas classificadas como Monumentos Nacionais e, como tal, de interesse nacional ao representar um valor cultural significativo para o país.

Acompanhando Garrett,

[...] rodeámos o largo e fomos entrar em Marvilla pelo lado do norte. Estamos dentro dos muros da antiga Santarem. Tam magnífica é a entrada, tam mesquinho é agora tudo ca dentro $[\ldots . .$.$] . Seguimos a triste e pobre rua Direita, centro do debil commercio que ainda$

\footnotetext{
3 O Convento de Nossa Senhora de Jesus do Sítio foi fundado, em 1592, para albergar os frades da Ordem Terceira de São Francisco. Possui duas torres sineiras e quatro capelas laterais, sendo que, no século XIX, foi aí instalado o Hospital de João Afonso (conselheiro de D. João I [1357-1433]). Atualmente, é a sede dos serviços da Santa Casa da Misericórdia de Santarém, estando classificado como Monumento Nacional por Decreto de 8 de agosto de 1923.

${ }^{4}$ O Convento de São Domingos das Donas foi fundado no século XIII, destinando-se a freiras da ordem dominicana. Foi extinto em 1895, aquando da morte da última freira, e transformado em quartel militar e em quartel da polícia, o que originou a demolição da igreja e de cujo acervo subsistem apenas algumas peças, como uma pia de água benta e vários painéis de azulejos.
} 
aqui ha $[\ldots]$. Ca está a curiosa tôrre das Cabaças, ${ }^{5}$ a velha egreja de San' João $[\ldots]$ (idem: 16-17).

Criticando o abandono dos edifícios e a degradação que se propaga pela localidade, o autor faz uma viagem no tempo, aludindo a alguns dos exemplares de arquitetura e enunciando diferentes locais de visita, numa digressão por monumentos de várias épocas que dão a conhecer a história de Santarém e, consequentemente, a história do país, permitindo que, tal como José Saramago (1994: 7) refere, “[... ] o viajante viaj[e] no seu país. Isto significa que viajou por dentro de si mesmo, pela cultura que o formou e está formando [...]. A felicidade [... tem muitos rostos. Viajar é, provavelmente, um deles [... ]".

Garrett desloca-se para a casa de Passos Manuel, situada junto à "[... ] famosa e historica egreja de Sancta Maria da Alcaçova7 [...]” (Garrett, 1846b: 17). Conquistado em 1147, por D. Afonso Henriques (1109-1185), que doou o direito eclesiástico da povoação à Ordem dos Templários, o Castelo de Santarém foi o espaço do Paço Real, permanecendo, atualmente, o recinto fortificado; duas portas de acesso à vila - a Porta de Santiago (ou porta da Alcáçova, que era a porta principal do castelo, atravessada, hoje, por inúmeros peregrinos do caminho de Santiago) e a Porta do Sol (presentemente, varanda panorâmica, onde se encontra instalado o Urbi Scallabis - Centro de Interpretação que apoia o conhecimento acerca do centro histórico) -; e ainda alguns troços das muralhas, classificados como Imóvel de Interesse Público, por Decreto de 14 de março de 1917, representando também um valor cultural de importância nacional.

Este espaço encontra-se ocupado pelo jardim das Portas do Sol, considerado o cartão de visita de Santarém, de cujo miradouro se pode contemplar a paisagem inspiradora que se desfruta sobre o rio Tejo e sobre a lezíria ribatejana:

[...] No fundo de um largo valle aprazivel e sereno, está o socegado leito do Tejo, cuja areia ruiva e resplandecente apenas se cobre d'agua juncto às margens, d'onde se debruçam verdes e frescos ainda os salgueiros que as ornam e defendem. D’além do rio [...] ], os riccos olivedos d'Alpiarça e Almeirim; depois a villa de D. Manuel e a sua charneca e as suas vinhas. D'aquem a immensa planicie [...], semeada de casas, de aldeias, de hortas, de grupos de árvores sylvestres, de pomares [... ] (idem: 24-25).

\footnotetext{
${ }^{5}$ A Torre das Cabaças, também conhecida como Torre do Relógio, data de meados do século XV. Em forma de paralelepípedo, o nome derivou da colocação de oito vasilhas de barro (cabaças) numa estrutura de ferro que suporta um sino de bronze de grandes dimensões e que servem de caixa de ressonância ao sino do relógio. A memória popular considerou significarem as "cabeças ocas" dos vereadores que decidiram erguer aquele maciço fortificado. Está classificada como Monumento Nacional por Decreto de 3 de fevereiro de 1928 e, desde finais do século XX, passou a constituir o Núcleo Museológico do Tempo.

${ }^{6}$ A Igreja de São João de Alporão data do século XII, tendo pertencido à Ordem dos Hospitalários e constituindo um edifício ímpar na arquitetura portuguesa, no qual coexistem influências românicas e góticas. No século XIX, o edifício foi devastado, passando a servir como teatro. Hoje em dia, nele está instalado o Núcleo Museológico de Arqueologia e Arte, integrando o Museu Municipal de Santarém. Está classificada como Monumento Nacional por Decreto de 23 de junho de 1910.

${ }^{7}$ A Igreja de Santa Maria da Alcáçova foi fundada na segunda metade do século XII, após a conquista de Santarém aos mouros, e a sua construção teve a iniciativa dos cavaleiros templários, cuja posse passou, mais tarde, para a Ordem de Santo Agostinho. Em 1280, foi aí estabelecida a Real Colegiada de Santa Maria da Alcáçova. Durante a Idade Média, instalou-se uma escola que se manteve até ao século XVIII. A fachada, precedida por um alpendre, é encimada por uma torre sineira. Está classificada como Imóvel de Interesse Público por Decreto de 25 de junho de 1984.
} 
Enfatizando a paisagem, numa experiência sensorial que desperta o colorido, a frescura, a fertilidade dos solos e a aglomeração dos povoados, Almeida Garrett revela o amor profundo que nutre pelo seu país, cujo sentimento é desvanecido pelo desencanto que experiencia ao visitar Santarém, de forma mais profunda:

[...] Ricco de illuminuras, de recortados, de florões, de imagens, de arabescos e arrendados primorosos, o livro era o mais bello e o mais precioso de Portugal. Inquadernado em esmalte de verde e prata pelo Tejo e por suas ribeiras, fechado a broches de bronze por suas fortes muralhas gothicas, o magnífico livro devia durar sempre [...]; mas esse povo cahiu em infancia, deram-lhe o livro para brincar, rasgou-o, mutilou-o, arrancou-lhe folha a folha [...] (idem: 32).

Através da metáfora, que alia as três características fundamentais de Santarém - a natureza, a arte e a história -, Garrett revela o seu desapontamento perante a incapacidade que os políticos demonstram face à preservação cultural daquele "livro de pedra", o qual se encontra devastado e em ruínas.

Daí a importância crucial do turismo que, existindo em prol das localidades, visando a divulgação das belezas naturais e a defesa do património artístico, pretende evidenciar, dinamizar e revalorizar os lugares, sendo também esse o propósito desta visita turístico-literária: “[...] 0 turismo valoriza o património pela exposição que lhe dá e ganha com os visitantes que o património atrai [... ]" (Brito, 2011: 135). Numa reciprocidade entre turismo e literatura, o objetivo consiste em valorizar os lugares referenciados no texto literário e estabelecer a relação entre a produção literária e o turista literário: “[... ] Os lugares literários são [...] os únicos elementos tangíveis a que o turista-leitor pode aceder, visitar e incluir no itinerário da viagem, e, por esse motivo, são, por excelência, os pontos de encontro dos leitores-turistas com os autores, as obras e as personagens [...]" (Quinteiro \& Baleiro, 2017: 54).

Garrett narra, entretanto, a história de Santa Iria ou Irene ${ }^{8}$ que dá o nome a Santarém, continuando a orientar a visita: "[...] Inclinando um pouco à direita, démos na celebrada porta de Atamarma, ${ }^{9}$ por [onde] entrou D. Affonso Henriques [... ]" (Garrett, 1846b: 104).

E prossegue: "Inclinámos o nosso caminho para a esquerda, e fomos passar deante do arrendado e elegante frontispicio gothico da Graça ${ }^{10}[\ldots]$ ” (idem: 111), descendo,

\footnotetext{
${ }^{8}$ Nascida numa família rica da Nabância (região de Tomar), Iria era uma noviça bela e inteligente, cujos atributos eram disputados por vários rapazes, entre os quais, o príncipe Britaldo. Iria confessou a sua eterna devoção a Deus e Britaldo aceitou a sua decisão. Todavia, passado algum tempo, o jovem ouviu rumores de que Iria atraiçoara a sua promessa e amava outro homem. A jovem foi assassinada e lançada à água e o seu corpo foi levado do rio Nabão até ao Zêzere e daí ao Tejo, sendo encontrado junto de Scallabis, encerrado num sepulcro de mármore, aí permanecendo incorruptível. O povo rendeu-se ao milagre e a localidade passou a chamar-se Sancta Irene.

9 Esta porta dava acesso ao lado da Ribeira, tendo sido demolida, devido ao estado de degradação e ameaça de ruína.

${ }^{10}$ A Igreja de Santa Maria da Graça ou de Santo Agostinho começou a ser construída em 1380 por iniciativa dos Agostinhos de Lisboa, ficando concluída apenas no segundo quartel do século XV. Detentora de três naves às quais se acede pela escadaria da entrada, a igreja é iluminada pela rosácea e pelas fenestras que se abrem nas naves. No século XIX, o convento foi fechado e vendido. Está classificada como Monumento Nacional por Decreto de 23 de junho de 1910.
} 
posteriormente, à Igreja do Santo Milagre" e respetiva capela: “[... ] A visita ao Sancto-Milagre não é completa sem se ir ver a casa onde elle se operou. Conservou-se ella por alguns seculos em grande veneração, e em mil seiscentos e tantos se converteu porfim em capella [...]" (idem: 116).

Após o jantar, na casa do amigo, Almeida Garrett desce até à Ribeira (velho burgo ligado ao tráfego fluvial que fez de Santarém a Porta do Ribatejo), "[... ] o suburbio democratico da nobre villa, hoje o ricco e o forte d'ella [...]. Por aqui se faz quasi todo o commercio da Extremadura e Beira com o Alemtejo [... ]: é a unica parte viva de Santarem [... ]" (idem: 122).

Seguindo o autor:

[... ] Ca estamos no Collegio, ${ }^{12}$ edificio grandioso, vasto, magnífico, propria habitação da companhia-rei que o mandou construir para educar os infantes seus filhos [... ]. O edificio do Collegio é todo philippino, ja o disse: a egreja dos mais bellos specimens d'esse stylo, que em geral sêcco, duro e sem poesia, não deixa comtudo de ser grandioso [...] (idem: 134-135).

Com Garrett, saímos do Colégio e dirigimo-nos a S. Domingos, ${ }^{13}$ “"[... ] um dos mais antigos estabelecimentos monasticos do reino [...]" (idem: 136). Aqui, o autor fica desiludido, visto que não consegue visitar a capela e o túmulo de S. Frei Gil (1190-1265), um médico e frade português, falecido em Santarém e beatificado em 1748. Após a guerra civil de Oitocentos e pelo decreto referente à extinção das ordens religiosas, o convento dominicano de Santarém foi vendido e destruído, sendo que do túmulo de São Frei Gil apenas resta a tampa com a sua figura esculpida em alto-relevo.

Segundo o autor, o corpo de S. Frei Gil desaparecera, porque fora trasladado para o mosteiro das Claras, ${ }^{14}$ aquando da expulsão das ordens religiosas, em 1834 e, com ele, "[... ] entremos n'esse convento das pobres Claras, tam afflictas e desconsoladas agora que as ameaçam de dissolução como aos frades [... ]" (idem: 142), seguindo-se o "[... ] real convento

\footnotetext{
${ }^{11} \mathrm{~A}$ Igreja do Santo Milagre foi fundada no século XIII, sendo inicialmente denominada de Igreja de Santo Estêvão. Em 1266, com a ocorrência do Santíssimo Milagre, passou a designar-se de Santo Milagre, acolhendo as relíquias sagradas. Segundo a lenda, uma mulher roubara uma hóstia para a entregar a uma feiticeira. Contudo, no caminho, o véu, que envolvia a hóstia, começou a escorrer sangue, pelo que a mulher se viu obrigada a escondê-la numa arca. Durante a noite, uma intensa luz, vinda da arca, inundou a casa. $O$ caso foi descoberto e a hóstia foi devolvida à igreja, onde está guardada numa custódia de prata dourada. A igreja está classificada como Monumento Nacional por Decreto de 14 de março de 1917.

${ }^{12} \mathrm{~A}$ Igreja de Nossa Senhora da Conceição do Colégio jesuíta foi construída a partir da década de 20 do século XVII, cuja conclusão ocorre em 1711. Durante a segunda metade do século XVIII, foi instalado, nos edifícios do Colégio, o Seminário Patriarcal de Santarém, passando a designar-se Igreja do Seminário. Mais tarde, foi elevada a Sé Catedral. $O$ interior apresenta uma só nave e capelas laterais, estando classificada como Monumento Nacional por Decreto de 14 de março de 1917.

${ }^{13}$ O Mosteiro de São Domingos, também conhecido por Convento de Nossa Senhora da Oliveira, foi fundado entre 1218 e 1225, pertencia à Ordem dos Pregadores e foi demolido no século XIX.

${ }^{14} \mathrm{O}$ Convento de Santa Clara estabeleceu-se em 1264, sendo que a sua construção remonta a 1259. Em 1902 , as suas portas encerraram, devido ao falecimento da última freira, pelo que o convento entrou em ruína e os seus bens foram vendidos. Em 1906, foram demolidos os edifícios conventuais, mantendo-se apenas a igreja, cuja iluminação resulta de uma rosácea e de múltiplas frestas e janelas. O edifício está classificado como Monumento Nacional por Decreto de 14 de março de 1917.
} 
de San' Francisco ${ }^{15}$ de Santarem [... ]" (idem: 153).

Expressando a sua mágoa face à decadência e à incúria a que foram votados muitos monumentos, Garrett exulta com a placidez da natureza que lhe concede um novo vigor, regressando a Lisboa: "[... ] Apenas comecei a respirar o ar fresco da manhan nos olivaes, senti desaffogar-se-me alma [... ]. Santarem fatigou-me o espirito [... ]. Deixo-a porêm com saudade, e não me heide esquecer nunca dos dias que aqui passei [... ]" (idem: 168).

Envolta em misticismo, dotada da história de um país e fronteira convergente entre a influência da grande metrópole e os ritmos da província, Santarém congrega a riqueza monumental com o património natural, tornando-se um destino turisticamente atrativo: “[... ] Santarem, Santarem, levanta a tua cabeça coroada de tôrres e de mosteiros, de palacios e de templos! Mira-te no Tejo, princeza das nossas villas: e verás como eras bella e grande, ricca e poderosa entre todas as terras portuguezas [... ]" (idem: 108).

\section{Considerações finais}

Portugal é um país de turismo, sendo que, atualmente, surgem muitas opções, como, por exemplo, o turismo de lazer, de saúde, religioso e cultural, em que a procura dos turistas se fundamenta, principalmente, na concretização de experiências personalizadas, como é o caso do turismo literário, que une viagens e literatura.

Assim, o conceito de turismo literário foi-se instalando, progressivamente, colocando novos espaços na rota de quem gosta de descobrir o que existe nos lugares onde os textos literários são criados.

Tal é o propósito da visita baseada em Viagens na Minha Terra de Almeida Garrett, a qual, reconstituindo o caminho efetuado pelo autor entre Lisboa e Santarém, através da sua jornada discursiva, com pontos de partida e pontos de chegada, explora os lugares referidos na obra, permitindo que os turistas-leitores se envolvam na diegese: "[... ] A vivência do espaço real onde a obra se enquadra permite ao leitor aumentar a polissemia da obra [... ]. O turista deixa de ser um mero recetáculo: ele passa a corredigir a paisagem e a obra [...]" (Carvalho \& Baptista, 2015: 57).

Na verdade, esta novela explora elementos do património português, não só cultural, histórico, natural e turístico, mas também literário, consciencializando para a importância da conservação do património, fomentando o interesse pela literatura e despertando a curiosidade dos leitores para a descoberta da região de Santarém: "[... ] Uma terra que possui o dom raríssimo de ser, ao mesmo tempo, uma vila antiga e uma cidade jovem [...]. É uma das poucas terras do país [... ] em que melhor se ausculta a aliança do passado e do moderno, do ontem e do amanhã, da História e do Progresso [... ]" (Serrão, 2008: 53).

Destacando a literatura como pretexto de viagem e como potenciadora da criação de lugares literários, como sucede com a obra de Garrett que refere ter "[...] visto alguma coisa do mundo, e apontado alguma coisa do que vi. De todas quantas viagens porêm fiz, as que mais me interessaram sempre foram as viagens na minha terra [... ]" (Garrett, 1846b: 233), esta proposta visa alinhar lugares e palavras que atravessaram o tempo, permitindo contemplar

\footnotetext{
${ }^{15}$ O Convento de São Francisco foi fundado em 1242, aquando do estabelecimento dos franciscanos em Portugal. Com a extinção das ordens religiosas, o edifício foi transformado em aquartelamento militar, sendo que, mais tarde, foi devastado por um incêndio, tendo reaberto em 2009. Está classificado como Monumento Nacional por Decreto de 14 de março de 1917.
} 
espaços, relembrar memórias e descobrir a riqueza histórico-cultural de Portugal, através da diversificação da oferta turística, alicerçada na promoção e na dinamização dos lugares.

No futuro, será pertinente desenvolver um itinerário disponibilizado em diferentes suportes (papel e aplicações para smartphone e tablet) com a respetiva tradução noutras línguas ao qual os turistas poderão aceder, flexibilizando a sua visita e alargando-a a outras nacionalidades.

\section{Referências}

Almeida, M. M. \& Oliveira, L. B. (2018). Os caminhos d' O Conspirador. Marvão: Câmara Municipal de Marvão.

Azevedo, C. de (1975). Arte monumental portuguesa (vol. 4). Porto: Portugráfica.

Baleiro, R. \& Quinteiro, S. (2017). Construção de um passeio literário: Cândido Guerreiro e a aldeia de Alte. Loulé: Câmara Municipal de Loulé.

Barros, V. (2015). Turismo em Portugal. Lisboa: Fundação Francisco Manuel dos Santos.

Brito, S. P. (2011). Direcção-Geral do Turismo: Contributos para a sua história. Lisboa: Imprensa NacionalCasa da Moeda.

Buescu, H. (1997). Dicionário do romantismo literário português. Lisboa: Caminho.

Carvalho, I. \& Baptista, M. M. (2015). Perspetivas sobre o turismo literário em Portugal. Revista Turismo \& Desenvolvimento, 24, 55-68.

Collot, M. (2012). Rumo a uma geografia literária. Gragoatá, 33, 17-31. (Trad. I. Alves). (Este artigo foi originalmente publicado em francês em Le partage des disciplines, LHT, Dossier, publicado em $16 / 3 / 2011)$.

Costa, C. (2005). Turismo e cultura: Avaliação das teorias e práticas culturais do sector do turismo (19902000). Análise Social, XL (175), 279-295.

França, J.-A. (1993). Garrett ou a ilusão desejada. In J.-A. França (Ed.), O romantismo em Portugal: Estudo de factos socioculturais (pp. 109-126). Lisboa: Livros Horizonte.

Garrett, A. (1846a). Viagens na minha terra. Lisboa: Typographia Gazeta dos Tribunaes.

Garrett, A. (1846b). Viagens na minha terra. Lisboa: Typographia Gazeta dos Tribunaes.

Instituto Nacional de Estatística. (2018). Estatísticas do turismo 2017. Lisboa: Instituto Nacional de Estatística.

Monteiro, O. P. (1976). Algumas reflexões sobre a novelística de Garrett. Colóquio/ Letras (30), 13-29.

Neves, A. (2010). Viagem pela literatura... e pelos espaços do mundo (ir)real. In E. Cordeiro (Ed.), Dinâmicas de rede no turismo cultural e religioso (vol. 2, pp. 265-276). Maia: Edições ISMAI.

Organização Mundial do Turismo das Nações Unidas/World Tourism Organization. (2017). Disponível em www2.unwto.org

Quinteiro, S. \& Baleiro, R. (2017). Estudos em literatura e turismo: Conceitos fundamentais. Universidade de Lisboa.

Quinteiro, S., Baleiro, R. \& Santos, I. D. (2016). Literatura e turismo: Viagens, relatos e itinerários. Faro: Universidade do Algarve.

Régio, J. (1994). Crítica e ensaio / 1. Lisboa: Círculo de Leitores.

Robinson, M. (2004). Narrativas de estar noutro sítio: Turismo e literatura turística. In A. Lew, C. M. Hall e A. Williams (Eds.), Compêndio de turismo (pp. 341-353). Lisboa: Instituto Piaget.

Saramago, J. (1994). Viagem a Portugal. Lisboa: Caminho.

Serrão, J. V. (2008). Páginas da história de Santarém (vol. 1). Lisboa: Academia Portuguesa de História. Serrão, V. (1990). Santarém. Lisboa: Editorial Presença.

Torga, M. (2015 [1950]). Portugal. Alfragide: Leya. 
ANA CLÁUDIA BOAVIDA SALGUEIRO DA SILVA é doutorada em Literatura pela Universidade de Évora e licenciada em Ensino de Português/Francês pela Escola Superior de Educação de Portalegre. Tem desenvolvido trabalho de investigação na área da Literatura, sendo autora de comunicações e artigos publicados em revistas científicas. É membro da Associação Portuguesa de Literatura Comparada, da International Comparative Literature Association e membro colaborador do Centro de Estudos em Letras da Universidade de Évora. Tem participado em colóquios, jornadas, conferências e congressos. Endereço institucional: Centro de Estudos em Letras (CEL), Universidade de Évora, Palácio do Vimioso, Largo Marquês de Marialva, 8, 7000-809 Évora, Portugal.

Submetido em 9 janeiro 2018

Aceite em 27 julho 2018 